\title{
Adjuvant vitamin $\mathbf{C}$ treatment in sepsis-how many oranges a day keep (vasopressor-dependent) septic shock away?
}

\author{
Patrick M. Honore, Rita Jacobs, Inne Hendrickx, Elisabeth De Waele, Herbert D. Spapen \\ ICU Department, Universitair Ziekenhuis Brussel, Vrije Universiteit Brussel, Brussels, Belgium \\ Correspondence to: Prof. Patrick Honore, MD, PhD, FCCM. ICU Department, UZ Brussel-VUB University, 101, Laarbeeklaan, 1090 Jette, Brussels, \\ Belgium. Email: Patrick.Honore@az.vub.ac.be.
}

Submitted Jul 07, 2016. Accepted for publication Jul 20, 2016.

doi: $10.21037 /$ jtd.2016.08.60

View this article at: http://dx.doi.org/10.21037/jtd.2016.08.60

Vitamin C is an essential water-soluble vitamin that is involved in many biosynthetic and metabolic processes. In healthy fasting humans, circulating levels of ascorbate, the redox form of vitamin $\mathrm{C}$, are typically in the range of $50-70 \mu \mathrm{mol} / \mathrm{L}$ (1). Levels $<25 \mu \mathrm{mol} / \mathrm{L}$ reflect marginal deficiency (hypovitaminosis C). Severe (scurvy-like) vitamin $\mathrm{C}$ deficiency is present when levels fall below $10 \mu \mathrm{mol} / \mathrm{L}$ (2). In the critical care setting, vitamin $\mathrm{C}$ is particularly notorious for its strong immunomodulating and antioxidant activity. As such, vitamin $\mathrm{C}$ is promoted as adjuvant therapy in conditions characterized by excessive oxidative stress or crippled immunity such as ischemia-reperfusion disorders, trauma, and various inflammatory disease processes (3).

Controlled studies on the effect of vitamin C in critically ill patients are scarce. Moreover, study outcomes are difficult to interpret because heterogeneous patient populations are studied, different and mostly low doses of vitamin $\mathrm{C}$ are used, oral and intravenous vitamin $\mathrm{C}$ regimens are mixed, and other antioxidative agents (e.g., vitamin $\mathrm{E}$ and selenium) are often associated (3). Most relevant experience with adjuvant vitamin $\mathrm{C}$ has been obtained in severe burn injury. Adding a high-dose vitamin $\mathrm{C}$ to standard fluid resuscitation significantly reduced fluid requirements and net fluid balance in a sheep burn model (4). Two small studies in burn patients assessed the effect of high-dose vitamin C (66 mg/kg/hour) given within the first 24 hours after thermal injury. One prospective study randomized patients to receive fluid resuscitation with or without adjuvant vitamin C. Vitamin C treatment reduced resuscitation volume and resulted in better gas exchange and less days on mechanical ventilation (5). A more recent retrospective study confirmed reduced fluid requirements and also reported an increased urinary output in vitamin $\mathrm{C}$ recipients (6). Both studies could not demonstrate a mortality benefit.

Evidence is emerging that parenteral administration of high-dose vitamin $\mathrm{C}$ may be a beneficial adjuvant therapy of severe sepsis and septic shock. An excessive inflammatory response indeed enhances metabolic turnover of vitamin C. As a result, patients with severe sepsis often have very low plasma vitamin $C$ levels that sometimes enter the "scurvy" zone (7). In animal models of sepsis, intravenous ascorbate rapidly and persistently improved capillary and microcirculatory blood flow, decreased microvascular permeability, and attenuated inflammation. Vitamin C also restored endothelial barrier function, prevented apoptosis, and exerted antibacterial effects $(3,8)$. Additionally, vitamin $\mathrm{C}$ acts as a cofactor to optimize activity of the enzymes dopamine $\beta$-hydroxylase and peptidylglycine $\alpha$-amidating monooxygenase which synthesise respectively norepinephrine and vasopressin $(9,10)$. This opens perspectives to use vitamin $\mathrm{C}$ for diminishing exogenous vasopressor need in clinical septic shock (11).

Despite these robust experimental benefits, few studies have evaluated the effect of vitamin C supplementation in human sepsis. Fowler et al. studied intravenous infusion of 50 or $200 \mathrm{mg} / \mathrm{kg} /$ day ascorbic acid every 6 hours for 4 days in patients with severe sepsis. As compared with placebo, patients receiving ascorbic acid exhibited less inflammation and prompt reduction of organ failure (12). Zabet et al. compared infusion of $25 \mathrm{mg} / \mathrm{kg}$ ascorbic acid every 6 hours for 72 hours with placebo in a small cohort of patients with septic shock who required norepinephrine treatment. During the study period, mean dose of norepinephrine and duration of norepinephrine infusion were significantly 
lower in the ascorbic acid than in the placebo group. Moreover, subjects who received ascorbic acid had lower 28-day mortality (13). In both studies, ascorbic acid infusion was well-tolerated and devoid of adverse effects.

Many important issues must be addressed before vitamin $\mathrm{C}$ can be incorporated in sepsis treatment protocols. The most effective dose and the best time for administration remain to be determined. Under normal physiological conditions, 100 to $300 \mathrm{mg}$ vitamin C per day is sufficient to reach adequate plasma concentrations (14). In contrast, up to $3 \mathrm{~g}$ daily is needed to restore normal plasma concentrations in critically ill patients (15). Highdose vitamin $\mathrm{C}$ infusion resulted in a 20 to 500 -fold (!) increase in ascorbic acid plasma concentrations $(5,12)$, yet a pharmacological dose (concentration)/effect has not been identified. Also, it is not known whether septic patients with normal or slightly decreased vitamin C levels may benefit from supraphysiologic supplementation. Hyperoxaluria and formation of calcium-oxalate stones in the kidneys is a potential adverse effect associated with high-dose vitamin $\mathrm{C}$ administration (16). However, a brief course of highdose ascorbate is unlikely to elevate the risk of oxalate stone formation, except in patients with uncontrolled severely impaired renal function. Septic shock patients are increasingly initiated on continuous renal replacement therapy (CRRT). Vitamin C is substantially cleared by dialysis (17) and at least $50 \%$ of ascorbate may be lost during CRRT (18). Current guidelines recommend a high, albeit still within physiological range, vitamin $\mathrm{C}$ dose during CRRT (17) which probably by no means guarantees to cover the needs in critically ill patients. Moreover, the daily intravenous dose in subjects with vasopressor-dependent septic shock treated with CRRT should probably even be higher. A temporary increase of up to $12 \mathrm{~g}$ per day has been suggested (18). "Stress" doses of steroids are commonly administered in patients with vasopressor-dependent or refractory septic shock. Steroids increase cellular vitamin C uptake (19) whereas vitamin $C$ may restore glucocorticoid receptor function (20). This potentially relevant synergistic effect should be elaborated in future trials. Toxicity of high-dose vitamin $\mathrm{C}$ has not been reported in published clinical trials. However, theoretical concerns exist that a high vitamin $\mathrm{C}$ intake might cause pro-oxidant effects, excess iron absorption, vitamin B12 deficiency, or allergic reactions. It is wise to avoid large doses of ascorbate in patients with a history of oxalate nephrolithiasis or in documented glucose-6-phosphate dehydrogenase deficiency, paroxysmal nocturnal hemoglobinuria, and hereditary hemochromatosis.

Awaiting the results of ongoing clinical trials investigating vitamin $\mathrm{C}$ supplementation in vasopressor-dependent septic shock, following recommendations can be made. A baseline vitamin $\mathrm{C}$ concentration must be obtained in all patients. Vitamin C should be given if levels are below $25 \mu \mathrm{mol} / \mathrm{L}$. In patients not treated with CRRT, 3 to $6 \mathrm{~g}$ vitamin $\mathrm{C}$ daily should be supplemented as long as vasopressor treatment is required. If CRRT is running, this dose can be temporarily increased to $12 \mathrm{~g}$ per day.

\section{Acknowledgements}

None.

\section{Footnote}

Conflicts of Interest: The authors have no conflicts of interest to declare.

Comment on: Carr AC, Shaw GM, Fowler AA, et al. Ascorbate-dependent vasopressor synthesis: a rationale for vitamin $\mathrm{C}$ administration in severe sepsis and septic shock? Crit Care 2015;19:418.

\section{References}

1. Vitamin C-Fact Sheet for Health Professionals. National Institutes of Health. Office of Dietary Supplements. Available online: https://ods.od.nih.gov/factsheets/ VitaminC-HealthProfessional/

2. Lykkesfeldt J, Poulsen HE. Is vitamin C supplementation beneficial? Lessons learned from randomised controlled trials. Br J Nutr 2010;103:1251-9.

3. Oudemans-van Straaten HM, Spoelstra-de Man AM, de Waard MC. Vitamin C revisited. Crit Care 2014;18:460.

4. Dubick MA, Williams C, Elgjo GI, et al. High-dose vitamin $\mathrm{C}$ infusion reduces fluid requirements in the resuscitation of burn-injured sheep. Shock 2005;24:139-44.

5. Tanaka H, Matsuda T, Miyagantani Y, et al. Reduction of resuscitation fluid volumes in severely burned patients using ascorbic acid administration: a randomized, prospective study. Arch Surg 2000;135:326-31.

6. Kahn SA, Beers RJ, Lentz CW. Resuscitation after severe burn injury using high-dose ascorbic acid: a retrospective review. J Burn Care Res 2011;32:110-7.

7. Borrelli E, Roux-Lombard P, Grau GE, et al. Plasma concentrations of cytokines, their soluble receptors, and 
antioxidant vitamins can predict the development of multiple organ failure in patients at risk. Crit Care Med 1996;24:392-7.

8. Wilson JX. Evaluation of vitamin C for adjuvant sepsis therapy. Antioxid Redox Signal 2013;19:2129-40.

9. Levine M. Ascorbic acid specifically enhances dopamine beta-monooxygenase activity in resting and stimulated chromaffin cells. J Biol Chem 1986;261:7347-56.

10. Prigge ST, Mains RE, Eipper BA, et al. New insights into copper monooxygenases and peptide amidation: structure, mechanism and function. Cell Mol Life Sci 2000;57:1236-59.

11. Carr AC, Shaw GM, Fowler AA, et al. Ascorbatedependent vasopressor synthesis: a rationale for vitamin $\mathrm{C}$ administration in severe sepsis and septic shock? Crit Care 2015;19:418.

12. Fowler AA 3rd, Syed AA, Knowlson S, et al. Phase I safety trial of intravenous ascorbic acid in patients with severe sepsis. J Transl Med 2014;12:32.

13. Zabet MH, Mohammadi M, Ramezani M, et al. Effect of high-dose Ascorbic acid on vasopressor's requirement in septic shock. J Res Pharm Pract 2016;5:94-100.

14. Levine M, Padayatty SJ, Espey MG. Vitamin C: a concentration-function approach yields pharmacology and therapeutic discoveries. Adv Nutr 2011;2:78-88.

Cite this article as: Honore PM, Jacobs R, Hendrickx I, De Waele E, Spapen HD. Adjuvant vitamin C treatment in sepsishow many oranges a day keep (vasopressor-dependent) septic shock away? J Thorac Dis 2016;8(9):E993-E995. doi: 10.21037/ jtd.2016.08.60
15. Long CL, Maull KI, Krishnan RS, et al. Ascorbic acid dynamics in the seriously ill and injured. J Surg Res 2003;109:144-8.

16. Thomas LD, Elinder CG, Tiselius HG, et al. Ascorbic acid supplements and kidney stone incidence among men: a prospective study. JAMA Intern Med 2013;173:386-8.

17. Honoré PM, De Waele E, Jacobs R, et al. Nutritional and metabolic alterations during continuous renal replacement therapy. Blood Purif 2013;35:279-84.

18. Fehrman-Ekholm I, Lotsander A, Logan K, et al. Concentrations of vitamin C, vitamin B12 and folic acid in patients treated with hemodialysis and on-line hemodiafiltration or hemofiltration. Scand J Urol Nephrol 2008;42:74-80.

19. Fujita I, Hirano J, Itoh N, et al. Dexamethasone induces sodium-dependant vitamin $\mathrm{C}$ transporter in a mouse osteoblastic cell line MC3T3-E1. Br J Nutr 2001;86:145-9.

20. Okamoto K, Tanaka H, Makino Y, et al. Restoration of the glucocorticoid receptor function by the phosphodiester compound of vitamins $\mathrm{C}$ and E, EPC-K1 (L-ascorbic acid 2-[3,4-dihydro-2,5,7,8-tetramethyl-2-(4,8,12trimethyltridecyl)-2H-1-benzopyran-6-yl hydrogen phosphate] potassium salt), via a redox-dependent mechanism. Biochem Pharmacol 1998;56:79-86. 